\title{
ANTENAS DE TELEFONÍA CELULAR, DERECHOS FUNDAMENTALES Y RECURSO DE PROTECCIÓN (SENTENCIAS DE LA CORTE DE APELACIONES DE SANTIAGO, CORTE SUPREMA)
}

\author{
Comentario de Alejandro Durán Roubillard
}

Sentencia Corte de Apelaciones de Santiago, Rol 1416-2009

Santiago dieciocho de noviembre de dos mil nueve

Vistos y teniendo presente:

$1^{\circ}$.- Que en lo principal de la presentación de fojas 7, doña María Lucina Rodríguez Cuevas, abogada, recurre de protección en contra de la Administración Edificios Plaza Italia, representada por su administrador don Francisco Klein Lavin y contra la empresa de Telefonía Movistar por la instalación y puesta en funcionamiento de dos antenas de telefonía celular a menos de dos metros de las ventanas del departamento que habita junto a sus hijos;

Explica que no se han cumplido los requisitos legales pues no tienen autorización de la Subsecretaría de Telecomunicaciones, que ello les causa un daño psíquico y físico pues las antenas emiten un zumbido que se acrecienta con la quietud de la noche, provocándoles trastorno en el sueño. Pide que se ordene la inmediata suspensión del funcionamiento de las antenas emplazadas frente a las ventanas.

$2^{\circ}$.- Que en el informe agregado a fojas 32, don Manuel Enrique Klein Lavin señala que Telefónica Móviles Chile S.A. es arrendataria de espacios comunes del edificio y tiene dos antenas de micro celdas de transmisión sobre la marquesina ubicada en la esquina costado Norte y Poniente del Edificio ubicado en calle Vicuña Mackenna $\mathrm{N}^{\circ} 05$, conforme al contrato de arrendamiento otorgado ante Notario Público. Dicho contrato se otorgó de conformidad al Acuerdo del Comité de Administración de 23 de Julio de 2008 y Asamblea de Copropietarios de 10 de junio de 1998. La arrendataria debía realizar todos los trámites para el desarrollo del proyecto. En síntesis, sostiene que los eventuales daños que pudieren afectar a la recurrente son de responsabilidad de Movistar y no de la Administración del edificio por lo que pide su rechazo a su respecto;

$3^{\circ}$.- Que Telefónica Móviles Chile S.A., en su informe agregado a fojas 111, sostiene que el recurso no cumple las exigencias del artículo 20 de la Constitución Política de 
la República ya que no existen actos u omisiones arbitrarios ni ilegales ya que primeramente, es obligación de la empresa dotar y ampliar de cobertura para los teléfonos móviles a través de la instalación de antenas. Los espacios fueron arrendados de conformidad al Acta de Acuerdo del Comité de Administración y Asamblea de Copropietarios de 1998 y en ese lugar se efectuaron las instalaciones, habiéndose cumplido estrictamente con la normativa aplicable, otorgándose debidamente la concesión mediante Decreto Supremo Exento $\mathrm{N}^{\circ} 7$, de 5 de enero del presente año. Se ha cumplido también con la Ordenanza General de Urbanismo y Construcciones. No se ha probado que haya riesgo para la salud. La resolución $\mathrm{N}^{\circ} 403$ de la Subsecretaría de Telecomunicaciones, de 2008, reguló la densidad de potencia de las antenas, habiendo numerosa doctrina de los Tribunales, en el sentido que no hay daño a la salud psíquica o física de las personas. A continuación transcribe estudios efectuados en el extranjero respecto del daño o peligro para la integridad de las personas. No se divisa vulneración de normas constitucionales y más bien debió haberse presentado en un juzgado de policía local y no a través de este recurso. Pide el rechazo del recurso con costas;

$4^{\circ}$.- Que la actora acompañó a los autos un informe técnico de potencia, correspondiente a Avenida Providencia 039, departamento 1, efectuado por don Gabriel Colihuinca Melin, ingeniero eléctrico, inscrito en el Colegio respectivo en el número 994. En el estudio se concluye lo siguiente:

a) Los equipos no están instalados en la ubicación autorizada por Subtel pues la dirección no corresponde ya que el domicilio autorizado es Providencia 038 y están instalado en Providencia 05, 50 metros más al poniente.

b) El nivel de Rx-level va desde $55 \mathrm{dbm}$ a $85 \mathrm{dbm}$.

c) La densidad de potencia en los puntos a los cuales las personas tengan libre acceso en general, es de 435 micro Watt por centímetro cuadrado. En la especie, se registra un valor de 784 micro Watt por $\mathrm{cm}^{2}$.

$5^{\circ}$.- Que a fojas 83, se agregó informe de don Pablo Bello Arellano, Subsecretario de Telecomunicaciones. Expresa que de conformidad a los artículos 14 y 15 de la Ley $\mathrm{N}^{\mathrm{o}} 18.168$, la instalación y operación de antenas de telefonía móvil debe contar con autorización del Ministerio de Transportes y Telecomunicaciones y no se pueden iniciar los servicios sin que las obras e instalaciones hayan sido precisamente autorizadas. En el caso sublite señala lo siguiente:

a) Telefónica Móviles S.A. solicitó una modificación de su concesión en el sentido de instalar, operar y explotar 2 nuevas estaciones base, una de ellas en Avenida Providencia $\mathrm{N}^{\circ} 039$.

b) Se efectuaron los trámites de rigor, publicándose el decreto el 8 de febrero de 2009.

c) La solicitud de recepción de obra fue rechazada por la Subsecretaría, en atención a que la estación se encuentra ejecutada y ubicada en la azotea de Avenida Providencia $N^{\circ} 5$ y la autorizada es en Avenida Providencia No 039.

d) Telefónica ha solicitado que se aclare la dirección, modificándola desde Providencia $\mathrm{N}^{\circ} 05$ por Providencia 39 y 57 . La solicitud se encuentra en tramitación. 
e) El 5 de marzo de 2009 se efectuó una visita inspectiva al domicilio de la recurrente, ubicado en Avda. Providencia 05, depto. 1, con el fin de constatar los sistemas radiantes (antenas) ubicados frente a la ventana de dicho inmueble, realizando mediciones de potencia al interior de la propiedad y realizar un levantamiento de las instalaciones.

f) El resultado de la visita se consigna en el informe $\mathrm{N}^{\circ} 6741$, de 29 de abril de 2009, que en síntesis, consigna: la estación base no tiene solicitud de recepción de obras, se encuentra en el edificio de Avenida Providencia $\mathrm{N}^{\circ} 05$ y los sistemas radiantes en la cornisa del mismo edificio, piso $2^{\circ}$ del depto. 1 . Se ingresa a las instalaciones por el edificio de Avenida Providencia N ${ }^{\circ} 057$, no obstante la autorización es en Avenida Providencia No 039.

g) La denunciante, doña María Lucina Rodríguez Cuevas, dedujo recurso jerárquico en contra de los resultados de la investigación, la que se encuentra pendiente de resolución por el señor Ministro de Transportes y Telecomunicaciones.

h) Se formulan cargos en contra de Telefónica el 19 de mayo de 2009, por la irregularidades detectadas. La causa se encuentra en etapa probatoria.

i) La Subsecretaría ordenó que se suspendiera la operación de la estación base, la que se concretó el 11 de junio pasado.

j) En el informe $\mathrm{N}^{\circ}$ 6741, mencionado en al acápite f) anterior, el resultado de la medición efectuada en el lugar de la actora, arrojó un valor inferior al límite establecido en la normativa vigente.

$6^{\circ}$.- Que planteada de este modo la acción, el hecho que se denuncia es la instalación de dos antenas para el servicio de telefonía móvil en las marquesinas del $2^{\circ}$ piso, frente a las habitaciones del departamento $\mathrm{N}^{0} 1$, de Avenida Providencia $\mathrm{N}^{\circ} 05$, a una distancia de aproximadamente 2 a 3 metros de las ventanas de dicho inmueble. De los antecedentes aportados al proceso, queda en evidencia que dichos artefactos fueron colocados en ese lugar sin que existiera la autorización expresa de la comunidad de los edificios, reunida en Asamblea Extraordinaria. Asimismo, la instalación y operación de la antena base se ha efectuado con infracción al artículo 14 inciso $3^{\circ}$ de la Ley General de Telecomunicaciones.

$7^{\circ}$.- Que en este sentido, el único antecedente acompañado por la recurrida Telefónica Móviles Chile S.A., es la fotocopia de la escritura pública a la que se redujo la Asamblea Extraordinaria de Copropietarios Edificio Plaza Italia, celebrada el 10 de junio de 1998. En dicha acta se autorizó el arrendamiento respecto de los espacios comunes ubicados en la azotea del edificio ubicado Providencia $\mathrm{N}^{\circ} 039$ y los bordes o cornisas de la totalidad de las azoteas, esto es, no hay referencia alguna a las marquesinas ubicadas en el segundo piso. Por este motivo, se infringe la ley de copropiedad pues es la asamblea extraordinaria la única facultada para gravar y otorgar arrendamiento de las especies comunes de un edificio y no el comité de administración;

$8^{\circ}$.- Que en lo que concierne a la ley general de Telecomunicaciones, queda en evidencia con el mérito de lo informado por el Subsecretario del ramo, que se infringió el 
inciso $3^{\circ}$ del artículo 14 de la normativa señalada, por cuanto no se autorizó la instalación de una antena base en Avenida Providencia $\mathrm{N}^{\circ} 05$ sino que en Avenida Providencia $\mathrm{N}^{\circ}$ 039. Se formularon cargos a la empresa, encontrándose pendiente su resolución.

$9^{\circ}$.- Que, en la especie, por tanto, la actuación de los recurridos es catalogable como ilegal y además puede considerarse como arbitraria pues ha respondido a una mera discrecionalidad del Comité de Administración de la Comunidad y de la empresa que arrienda dichos bienes comunes y con los antecedentes que se han aportado a la casa, en especial del informe técnico de fojas 130 , mencionado en el motivo cuarto precedente y con el certificado otorgado por el doctor Georges Granger Huerta, se comprueba que, a lo menos, la proximidad de las antenas bases de los dormitorios que ocupan la recurrente y su familia, provoca una alteración en la actividad de los moradores, especialmente en horas de la noche, por cuanto dichas antenas emiten radiaciones variables y no uniformes que perturban y amenazan la integridad física y síquica de la actora y sus hijos, lo que debe ser tutelado por esta vía constitucional;

Atendido además lo dispuesto en el artículo 20 de la Constitución Política de la República y Auto Acordado de la Excma. Corte Suprema sobre la materia, SE ACOGE el recurso de protección deducido en lo principal de la presentación de fojas 7 , por doña María Lucina Rodríguez Cuevas y en consecuencia se declara que las dos antenas de telefonía celular, instaladas, en la marquesina del edificio ubicado en Avenida Providencia $\mathrm{N}^{\circ}$ 05, a dos metros del inmueble ocupado por la actora, deben ser retiradas de dicho lugar, otorgando un plazo de 20 días para tal cometido, a contar de la fecha que esta sentencia quede ejecutoriada.

Regístrese y archívese, oportunamente.

Redactó el Ministro Sr. Muñoz Pardo.

$\mathrm{N}^{\mathrm{o}} 1416-2009$.

No firma la Ministra señora Amanda Valdovinos Jeldes, no obstante haber concurrido a la vista y al acuerdo, por encontrarse en comisión de servicios.

Pronunciada por la Octava Sala de esta Corte de Apelaciones de Santiago, presidida por el Ministro señor Juan Manuel Muñoz Pardo e integrada por la Ministra señora Amanda Valdovinos Jeldes y por el Abogado Integrante señor Jorge Lagos Gatica.

Sentencia Corte Suprema, Rol 9055-2009

Santiago, trece de abril de dos mil diez.

\section{VISTOS:}

Se reproduce el fallo en alzada, con las siguientes modificaciones:

En el considerando cuarto, letra a), se sustituye el numeral "038" por "039" y lo escrito a continuación hasta el punto final, por la siguiente oración: “y están emplazados en Providencia 05, a una distancia de 50 metros más al poniente”. 
Se elimina el considerando noveno.

Y visto lo dispuesto en el Auto Acordado de esta Corte Suprema sobre la materia, SE CONFIRMA la sentencia de once de noviembre del año dos mil nueve, escrita de fojas 207 a 211 .

Regístrese y devuélvase con su agregado.

Redacción del Ministro Sr. Pedro Pierry Arrau.

Rol 9055-09.

Pronunciado por la Tercera Sala de esta Corte Suprema integrada por los Ministros Sr. Héctor Carreño Seaman, Sr. Pedro Pierry Arrau, Sra. Sonia Araneda Briones, Sra. Rosa del Carmen Egnem Saldías y el Abogado Integrante Sr. Alberto Chaigneau. No firma el Ministro Sr. Pierry, no obstante haber estado en la vista y acuerdo de la causa, por estar en comisión de servicios. Santiago, 13 de abril de 2010.

Autoriza la Secretaria de esta Corte Suprema Sra. Rosa María Pinto Egusquiza.

En Santiago, a trece de abril de dos mil diez, notifiqué en secretaria por el Estado Diario la resolución precedente.

\section{COMENTARio}

La noticia de haberse dictado las sentencias que se comentan parecía un interesante y radical giro en la jurisprudencia nacional, ya que hasta la fecha las Cortes habían rechazado sistemáticamente este tipo de acciones tutelares. Más relevancia adquiría este caso si se tiene presente que no se fundamentó la pretensión utilizando el reiterado y discutible recurso de sostener que se había afectado el derecho a la igualdad ante la ley, el derecho de propiedad u otros. El conflicto constitucional de fondo se planteó de manera directa, solicitando la recurrente el amparo de la garantía contemplada en el numeral $1^{\circ}$ del artículo 19, "pues las antenas emiten un zumbido que se acrecienta con la quietud de la noche, provocándoles trastorno en el sueño" a ella y sus hijos.

Los fundamentos sostenidos por los tribunales de justicia para rechazar este tipo de acciones tutelares se pueden resumir de la siguiente manera: 1) Que las empresas concesionarias instalan y operan sus antenas dando debido cumplimiento a las exigencias legales y reglamentarias pertinentes, por lo que al contar con todos los permisos administrativos respectivos no puede calificarse de ilegal o arbitraria su actividad; y 2) Que los presuntos efectos dañosos para la salud de la población que se atribuyen a esta clase de antenas, por la emisión de ondas electromagnéticas, es una materia que no es posible de determinarse en sede de protección, de carácter sumarísimo, menos aún tratándose de un asunto eminentemente técnico y científico, sobre el cual aún se discute y no hay conclusiones claras, definitivas o concluyentes ${ }^{1}$.

${ }^{1}$ Vid. v. gr. Corte Suprema, 01/08/2005, Rol 3.066-2005, confirmando sentencia CA de Santiago de fecha 07/06/05, Rol 568-2005 (No ID LegalPublishing: 32559). Corte Suprema, 10/11/2009, Rol 7.724- 
De lo expuesto puede comprenderse el interés en conocer y analizar en detalle los fundamentos que tuvieron las Cortes para modificar el criterio jurisprudencial sostenido por ellas mismas hasta hace pocos meses. Lamentablemente la revisión de las sentencias resulta desilusionante y las expectativas creadas se ven insatisfechas.

El pronunciamiento de la Corte de Apelaciones, acerca de la forma como la acción de las recurridas habría afectado la garantía fundamental de la recurrente, no parece suficientemente desarrollada como para justificar un cambio de criterio jurisprudencial tan asentado. En el considerando $9^{\circ}$ los sentenciadores sostienen que el funcionamiento de la antena constituye un atentado contra la salud física y/o síquica de la recurrente, no obstante lo informado por la Subsecretaría del ramo, que requerida al efecto expresó que "el resultado de la medición efectuada en el lugar de la actora, arrojó un valor inferior al límite establecido en la normativa vigente”. Sin explicar los motivos para desechar lo expuesto por la autoridad sectorial, el fallo de primera instancia se sostiene a partir de lo que señalan dos profesionales independientes, un ingeniero y un médico. El primero se limita a reportar que la medición realizada en el domicilio de la recurrente arrojó determinados valores, sin que se explique cuáles son los efectos que tales índices de emisión provocarían en la salud de las personas. El segundo emitió un certificado (no mencionado en la parte expositiva del fallo) al que la Corte le atribuye mérito suficiente para tener por acreditado que la proximidad de las antenas, sumado a la emisión de radiaciones variables y no uniformes, provoca una alteración en la actividad del grupo familiar, especialmente en horas de la noche, lo que bastaría para afirmar que tales emisiones perturban y amenazan la integridad física y síquica de la actora y sus hijos. Nuevamente la Corte de Apelaciones omite explicar fundadamente la razón para atribuirle mayor mérito probatorio al certificado médico, por sobre los estudios y antecedentes acompañados por la empresa recurrida. Pero, más importante aún, la Corte en definitiva no da respuesta a la cuestión de fondo: ¿De qué manera las emisiones de la antena y la presunta alteración de la actividad de los moradores afecta la integridad síquica y física de la actora y su grupo familiar? No se está afirmando que la conclusión sea errónea, sino que en este ámbito de tutela constitucional es exigible un grado certeza fáctica y de fundamentación que no se satisface en la sentencia referida.

Es más, esta carencia argumental se ve agravada en la sentencia de segunda instancia. La Corte Suprema se limita a hacer una rectificación menor en el considerando $4^{\circ}$ y elimina por completo el considerando $9^{\circ}$, para a continuación confirmar el fallo de primera sin mayor fundamentación. En definitiva, la sentencia de término ratifica la decisión de otorgarle tutela a la actora, pero sin hacer siquiera mención a que se hubiese efectivamente amagado, perturbado o afectado alguna garantía fundamental.

¿Cuál es entonces el fundamento para acoger el recurso de protección? Desechada por la Corte Suprema el único considerando referido a la materia constitucional de fondo, sólo se sostiene la decisión en la imputación a las recurridas de haber realizado una acción

2009, confirmando sentencia CA de Santiago de fecha 01/10/09, Rol 10.487-2008 (Gaceta Jurídica 353, pág. 33, No ID LegalPublishing: 42909). 
ilegal y arbitraria. Puede resumirse este reproche en dos circunstancias fácticas: 1) Al solicitarse la autorización de instalación de la antena y la modificación de concesión a la autoridad sectorial, la empresa telefónica cometió un evidente error al identificar el inmueble donde se emplazaría la estación base cuestionada; 2) La antena fue instalada en un espacio común distinto al que fue aprobado en la asamblea de copropietarios que sirvió de fundamento al contrato de arriendo suscrito por el Comité de Administración. Dicho de otra manera, de no haberse cometido estos errores en el proceso de instalación de la antena, siguiendo el criterio de las Cortes, el recurso debió haberse rechazado, puesto que no podría imputarse ilegalidad o arbitrariedad a la acción de las recurridas. ¿Son este tipo de conflictos administrativos y vecinales para los que se consagró en nuestra Constitución la tutela jurisdiccional de garantías fundamentales?

Mucho se ha dicho y escrito, incluso desde el propio Poder Judicial, criticando la arraigada costumbre de los abogados de recurrir de protección para resolver contiendas que deberían ventilarse mediante procedimientos de lato conocimiento y ante tribunales de base, recargándose en exceso e injustificadamente la labor de las Cortes. Esta crítica es fundada y efectiva, pero teniendo presente lo resuelto en este caso cabe preguntarse ¿la indebida utilización del recurso de protección es responsabilidad exclusiva de los abogados litigantes? Parece que no. 